\title{
A multimodal analysis of political satire: Webcomics and GIFs in Post-Arab Spring Egypt
}

\section{Hanem El-Farahaty}

University of Leeds, UK and University of Mansoura, Egypt

H.El-Farahaty@leeds.ac.uk

The Egyptian Revolution in 2011 and the protests known as "the Arab Spring" resulted in an increase in the number of comic writers and amateurs who use specialist software to mix modes digitally for novel sign-making (Gursimesk, 2016; Lankshear \& Knobel, 2008). These people draw creative forms of satire, including but not limited to political webcomics and Graphics Interchange Formats (GIFs) which exist alongside political cartoons. This article aims to employ a multimodal analysis of a sample of Egyptian webcomics and GIFs in order to highlight how visual design elements complement each other, in an effort to support translators and/or readers/viewers in their interpretation of the images and, by extension, in their ability to make sense of reality. With this aim in mind, this article combines Serafini's (2010) tripartite approach to perception, structure and ideology; Kress and van Leeuwen's (2006) discussion of elements of visual design, and Genette's and Maclean's (1991) approach to paratext. The analysis will also be informed by interviews with the founders and co-founders of two Facebook pages, and with a cartoonist working for Almasry Alyoum newspaper. First, the article discusses briefly the translation of comics or webcomics and GIFs, particularly the challenges of translating political webcomics and GIFs into English. The theoretical framework and a case study are then discussed in the second part.

\section{Introduction}

Since the 25 January Revolution, young Egyptian comic writers and amateurs have been designing visual images using specialist software to digitally mix modes for novel signmaking (Gursimsek, 2016; Lankshear \& Knobel, 2008). These creative forms of satire include but are not limited to political webcomics and Graphics Interchange Formats (GIFs), and they exist alongside political cartoons. Willems (2011) describes comics ${ }^{1}$ as a type of political satire that "may point fingers at those subject to power in an attempt to make readers cope with the tragic events unfolding around them" (p. 16). In Egypt specifically, online comic strips have attracted much attention following the 25 January Revolution. According to Gawish, founder of the webcomics Facebook page Elwarka/The Paper (see section 4.2), his page

is accessed by different age groups ranging from 10 to 60 , from various social and academic backgrounds, and is accessed and followed by people inside of Egypt as well as from the rest of the Arab world (Interview, 23 February 2017).

He also asserts that

in some cases people know the news from a comic I drew. I usually entitle the comic with news of the day to inform the followers of the current news, the comic receives lots of shares and likes than the news itself. (Interview, 23 February 2017) 
GIFs are "a form of web-based graphics which contain a series of frames. These frames can be used to create graphics in the form of looped moving images" (Gursimsek, 2016, p. 330). GIFs could also contain non-moving pictures. These forms of static GIFs consist of a number of panels that tell a narrative and they could be called comics (Sedky, Interview, 31October 2016). Sedky has further explained what is meant by a GIF in the following passage:

[D]rawing GIFs is different from drawing a cartoon, for the latter consists of one panel/frame providing a brief sarcastic message, but a GIF consists of more than one panel/frame and tells a short story about a current situation. We use film scenes, and adapt them to a situation that is being criticised, sometimes change them slightly (e.g., a character drinks tea instead of water) but we strictly follow the scenario of the original film in content and in form. (Interview, 31 October 2016)

This article uses static GIFs which are clearly identified from webcomics in that they use content from films and television; but the webcomics are drawn by the producer of the comic.

Semiotic resources used to create multimodal texts are different from those drawn on to create printed texts, and they bring with them different potentials for meaningmaking (Serafini, 2010, p. 86); for example, GIFs contain more multimodal resources than a traditional cartoon. Egyptian creators of GIFs often draw on televised content from films, plays or other performances that are popular and easily recognisable to the public. These are usually funny and memorable scenes involving the protagonist(s).

As these images contain multiple visual design elements (Kress \& van Leeuwen, 1996/2006) and paratextual elements (Genette \& Maclean, 1991), translators and/or readers/viewers must have some knowledge of these elements in order to be able to interpret the images. The aim of this article is therefore to highlight how visual design elements complement each other, in an effort to support translators and/or readers/viewers in their interpretation of the images. More specifically, this paper aims to identify a tool of analysis for multimodal texts and uses it to analyse a sample of Egyptian webcomics and GIFs. With this aim in mind, this paper attempts to address the following research questions: How may the reader's familiarity with multimodal meaning construction facilitate the reading of webcomics and GIFs?; and How can an understanding of multimodality help translators to convey the multimodal message?

To respond to these research questions, this article combines Serafini's (2010) tripartite approach to perception, structure and ideology; Kress and van Leeuwen's (1996/2006) discussion of elements of visual design, and Genette and Maclean's (1991) approach to paratext. The analysis is also informed by interviews with founders and cofounders of two Facebook pages, and with a cartoonist working for Almasry Alyoum newspaper (see section 4.2). First, the paper discusses briefly the translation of comics/webcomics and GIFs, particularly the challenges of translating political webcomics and GIFs into English. Secondly, the theoretical framework and a case study are discussed.

\section{Research on translating (web)comics and GIFs: A brief review}

Whereas, previously, research on the translation of comics was focused on the verbal mode, Kaindl $(1999,2004)$ was one of the first scholars to draw attention to visual elements. In 2004, for instance, he presented an approach which encompasses verbal and non-verbal aspects of humour in the translation of comics, discussing examples from Asterix and Tintin. O'Sullivan (2013) discussed the translation of multimodal texts and the challenges this multimodality poses for the translator and the "reader/consumer of these texts". In addition, she suggests that multimodality can also be a "resource for 
translation" (O'Sullivan, 2013, pp. 11-12). Zanettin's (2008) edited volume on the translation of comics, on the other hand, focuses on different genres and on a number of languages and cultures, examining the interplay between visual and verbal messages. In this work, Zanettin (2008) asserts that

the study of translated comics may provide useful insights into an understanding of translation as a complex process of intercultural communication, involving quite a few people and much more than simply the replacement of written text in speech balloons (p. 97).

In one of the chapters, Zitawi (2008), for example, applies Brown and Levinson's (1987) Politeness Theory to the translation of Disney comics into Arabic. In 2015, Borodo investigated the Franco-Belgian comic book series Thorgal and its Polish translations, highlighting the ways in which the textual and non-verbal modes interact and contribute to the creation of meaning on a multimodal page, and the transformations their relationship may undergo in translation. Veloso and Bateman (2013) analysed multimodal meaning construction in Marvel's comic series Civil War. They suggested that multimodal discourse analysis can show how particular discourse contexts of public opinion are propagated.

Comics in Arabic, to give an example, have been shaped by Western influence (Høigilt, 2017), and the majority are translations from English, such as Asterix, Tintin or the adult comic, Metro, which was first published in Egypt in 2008, then banned until 2013, when it was reprinted again. The Institute of Current World Affairs (2015) and The Arab Comix Project [online] traced the history and origin of Arabic comics, including the first occurrence of comics in the Arab World. Focusing on Egypt, Mehrez (2012) and Baker (2015) discussed the translation of street art, humour, poetics, myths, and cartoons, specifically in the context of the Egyptian Revolution. However, only a small number of articles discussed the translation of webcomics - a term coined by combining the abbreviation for "World Wide Web" (web) and the short form of "comic magazine" (comic) (Zanfei, 2008, p. 55). Mohamed (2015), for instance, reflected on the role language and translation play in radically transforming the content of the webcomic Qahira/Cairo. Having translated her own webcomic into Arabic, she highlighted the challenges she encountered as a result of feminist themes contained within the comic, as well as the uncertainty she felt about the reception of the content by an Arabic audience.

Multimodally oriented research on GIFs is scarce. As one of a few scholars examining this phenomenon, Gursimsek (2016) analysed the design of the transmedia television production, Lost. By discussing a case study of "the creation of GIFs within the Lost fan community on Tumblr", she focused on the role of GIFs in online communication as a transmedia literacy practice.

This brief review indicates that so far research has focused on translated comics and that GIFs have received little research attention. It also suggests that there is little research on translating or translated webcomics and/or GIFs in the Arabic context. This article aims to address this gap by identifying a tool of analysis useful for researchers and translators alike.

\section{Challenges of translating political webcomics and GIFs}

Following the Arab Spring, most political satire that has been translated in Egypt involves political cartoons (Makhlouf, Interview, 7 March 2017). Makhlouf, a professional cartoonist (see section 4.2), comments on the difficulty of translating political cartoons as follows: 
Cartoons are one form of popular art whose messages are closely related to the place and the culture of the cartoonist, the history of the people and their place (country). This makes the task of the translator very difficult. He or she needs to be well versed in both languages, to be aware of the strong comical element in the image. Despite all this, the message will not be completely transferred. It is easier to translate the image when it relates to a universal political incident. (Makhlouf, Interview, 7 March 2017)

This potentially rings true for any form of political satire, especially traditional satire drawn by professional cartoonists. Egyptian political webcomics and GIFs, much like any other form of political satire, abound with culture-specific elements which entail a "cultural difference in representation and meaning" (Kress, 2010, p. 8). More specifically, the language of political comics in Egypt, as in many other political systems and cultures, is "a realm of mixed metaphors and local jokes articulated in deep slang", which "provides a cover for overt criticisms of the government" (Guyer, 2017)).

Political webcomics and GIFs combine "the visual-text rhythm, the scene specifics and panel framing" (Asimakoulas, 2016, p. 574), which create a complex multimodal environment. Like all GIF producers who rely heavily on scenes from TV series and movies, Egyptian GIF producers use scenes from movies and plays from their source culture. It is this intertexuality - that is, references to other texts and genres (Kristeva, 1980) (on which many "memes" rely) - that contributes to the meaning. Therefore, and because a translation may retain the layout and framing of the GIF, an additional layer of difficulty to transferring the GIF's underlying socio-cultural narrative surfaces in the translation process. It is important to note that Egyptian webcomic writers and GIF designers are currently designing visual images abundant with anterior paratextual elements (Genette \& Maclean, 1991; see section 4.3), which is why translators and viewers of these images require some awareness of these elements in order to be able to interpret them appropriately. More specifically, any translation will have to respond to the textual and the visual mode and to the interrelations between them.

In effect, Arabic political webcomics and GIFs pose some challenges for translators as well as for the very process of translating (Salor \& Marasligil, 2013, p. 9). For example, Egyptian webcomics and GIFs do not necessarily contain elements of traditional cartoons, but often include the following:

(1) borrowing from Egyptian cinema and theatre

(2) introducing Western elements

(3) borrowing pan-Arab Spring issues

introducing religious elements. ${ }^{2}$

In the translation of political cartoons, it is thus arguably not sufficient to focus solely on the verbal mode. In fact, translations of political webcomics and GIFs need to respond to and highlight both the visual mode expressed by individuals (Gawish, Interview, 23 February 2017) and concrete images that make them culture-specific. ${ }^{3}$ By way of illustration, we can consider the translation of a GIF featuring the ousted Muslim Brotherhood president Mohamed Morsi. In it, he appears in court, wearing the outfit of the late Libyan president Gadhafi, addressing the president of the Supreme Court with "Who are you?" This statement was also uttered by Gadhafi in a speech in February 2011. This GIF therefore merges modes from two sociopolitical contexts: the visual mode represented by the image of Morsi in the outfit of Gadhafi, and the verbal mode represented by Gadhafi's words in Morsi's Egyptian dialect. Although merging two images on the visual mode may act as a visual clue to the viewer of the satirical element in the webcomic, this adds another layer of meaning that even the primary audience may find difficult to ascertain. These interlinked elements make the translation challenging when focusing on the verbal mode alone, but they demand further understanding as "any 
combination of modalities may be deployed for dramatic and narrative effect" (Veloso \& Bateman, 2013, p. 6). For this GIF, the translator therefore needs to establish links to its socio-political context, highlight the pan-Arab element in the image, and ultimately present a message as closely as possible to the one in the original.

\section{Theoretical framework}

This section introduces Serafini's (2010) tripartite framework of perception, structure and ideology, Kress and van Leeuwen's grammar of visual design (1996/2006) and Genette and Maclean's notion of paratext (1991).

\subsection{Serafini's tripartite approach}

Serafini (2010) proposes a framework for analysing multimodal texts based on perceptual, structural and ideological analytical perspectives. These are to be understood as circles embedded in further perspectives rather than as a hierarchy of levels (Serafini, 2010):

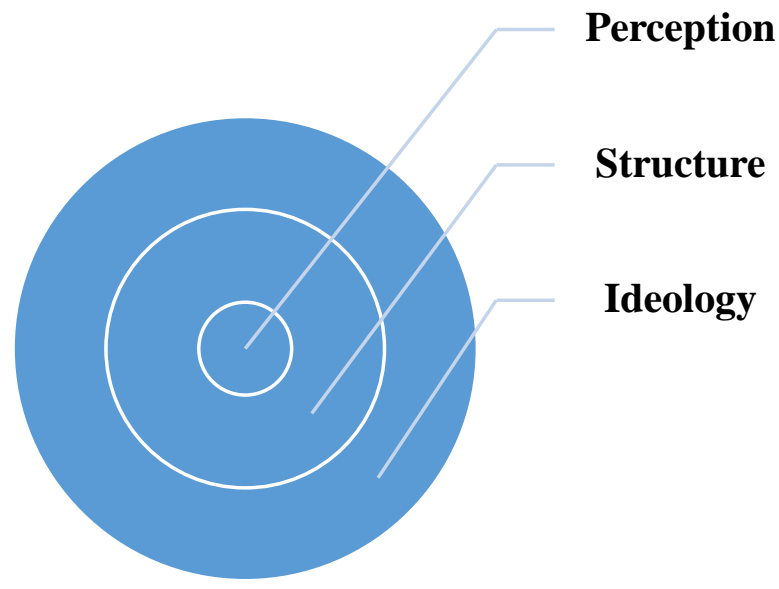

Figure 1: Serafini's Tripartite Framework

Perception, in this framework, is located at the centre. It refers to the design and visual elements of a multimodal text - in this case, a webcomic or a GIF - and the denotative meanings presented to the reader(s). It therefore focuses on the literal or denotative contents of an image or a series of images in a multimodal text, that is, elements of design, borders and font, as well as other visual and textual elements contained within these texts (Serafini, 2010, p. 92). Perception draws on the person's understanding of multimodal texts in relation to background knowledge, socio-cultural and historical perspectives and personal experiences (Serafini, 2010, p. 88). More specifically, perception prepares the viewer or reader to respond and interpret (Stolnitz, as cited in Serafini, 2010, p. 93). ${ }^{4}$

Structure considers image-text relations and their design. Therefore, interpretation of image design facilitates readers' understanding of the meaning intended by the image creator (Serafini, 2010). Serafini (2010, p. 95 and Serafini \& Ladd, 2008) highlight the concept of "naming", that is "to give language to an aspect of a visual image 
is an act of transduction - a shift from one mode (image) to another (language)". However, Serafini (2010, p. 95) stresses the importance of semiotic resources and grammars inherent in images and design elements as put forward by Kress $(2003,2010)$. Thus, "through socio-cultural uses and associations, metaphorical connections and synecdochal relationships these resources provide prompts from which viewers can construct meanings and interpretations" (Serafini, 2010, p. 96). Serafini's analysis of structure draws on Kress and van Leeuwen's (1996) taxonomy of structures of visual images, which will be discussed in section 4.2.

Ideology is influenced by perception and structure. Political images are important means to convey a message, and ideology is always embedded in them. To explore the meaning of images is to recognise that they are produced within the dynamics of social power and ideology (Sturken \& Cartwright, 2001 as cited in Serafini, 2010, p. 98). Ideology serves the function of performing social actions based on the design of the visual image and the perceptual qualities employed in it. The capacity of images to affect viewers is dependent on the cultural meanings they evoke, and on the social, political and cultural contexts in which they are viewed (Sturken \& Cartwright, 2001, as cited in Serafini, 2010, p. 98).

Serafini (2010) stresses the importance of combining the strategies developed by visual grammar and semiotics, proposed by Kress (2003) and Kress and van Leeuwen (1996/2006), visual communications, introduced by Leeds-Hurwitz (1993) and SmithShank (2004), and visual literacy, discussed by Duncum (2004). Serafini (2010, p. 86also asserts that more attention is to be given to the socio-cultural contexts of production and reception (See Aiello, 2006 for more information).

\subsection{Kress and van Leeuwen's elements of visual design}

Kress and van Leeuwen (2006) refer to three metafunctions of the structural design of the image, "representational, interpersonal and compositional", describing the basic elements of design and compositional structures as put forward by social semiotics (pp. 6-7). They characterise representation as:

a process in which the makers of signs, whether child or adult, seek to make a representation of some object or entity, whether physical or semiotic, and in which their interest in the object, at the point of making the representation, is a complex one, arising out of the cultural, social and psychological history of the sign maker, and focused by the specific context in which the sign maker produces the sign. (Kress \& van Leeuwen, 2006, p. 7)

According to Kress and van Leeuwen (2006, p. 48), there are two types of participant in every semiotic act: interactive and represented. Interactive participants are intended or implied people that can be derived from the image, for example through the way the whole image is framed, through its angle, and through the way its participants are represented and what this says about the projected identity of the producer of the image. Interactive participants also refer to the producers and the viewers of the image.

Represented participants, on the other hand, are

the people, places and things (including abstract "things") represented in and by the speech or writing or image, the participants about whom or which we are speaking or writing or producing images (Kress \& van Leeuwen, 2006, p. 48).

The Interpersonal metafunction then describes the interactive relations between the depicted participants (i.e., people and places) and interactive participants (i.e., producers and viewers) (Kress \& van Leeuwen, 2006, p. 114). 
Finally, then, composition, according to Kress and van Leeuwen (2006, p. 177), relates the representational and interactive meanings of the image to each other through three interrelated systems: (i) information value, "the placement of elements (participants and syntagms that relate them to each other and to the viewer)"; (ii) salience, "the elements made to attract the viewer's attention to different degrees, as realized by such factors as placement in the foreground or background, relative size, contrasts in tonal value (or colour), etc."; and (iii) framing, "the presence or absence of framing devices (realized by elements which create dividing lines, or by actual frame lines)".

The metafunctions of visual design described here are derived from Halliday's $(1985 / 2014)$ three metafunctions of verbal language: ideational, interpersonal and textual. Ideational describes the content of the text or proposition, the participants involved and the circumstances of an event. The interpersonal describes text or speech functions, for example, declarative to express the speaker's angle or interrogative to establish the listener's angle (Halliday, 1985/2014, p. 192). Textual relates to the flow of information (Halliday, 1985/2014, p. 192) in a text and how "the elements of the text cohere internally, and which itself coheres with its relevant environment" (Kress \& van Leeuwen, 2006, p. 15). The three metafunctions are interlinked, that is, the ideational has to "piggy-back on the interpersonal" and vice versa (Andersen, Morten, Maagerø, \& Tønnesen, 2015, pp. 106-107). However, in one mode one of the metafunctions can indeed be predominant (Andersen et al., 2015, pp. 106-107), and in all cases the reader's and/or the viewer's interpretation of the image's meanings depends on "their experiences, culture, and knowledge of social and image conventions" (Serafini, 2010, p. 97).

\subsection{Genette and Maclean's paratext}

Genette and Maclean (1991) define paratext as "the means by which a text makes a book of itself and proposes itself as such to its readers, and more generally to the public" ( $p$. 261). The characteristics of the paratext involve "spatial, temporal, substantial, pragmatic, and functional" features (Genette \& Maclean, 1991, p. 261).

Spatial paratextual features consist of two elements: "peritext" and "epitext" (Genette \& Maclean, 1991, p. 264). The former describes paratextual features that are positioned in relation to the text itself, for example, the titles of the chapters of a book; the latter describes paratextual elements situated outside the book itself, for example, interviews or private communication. Temporal paratexts are (i) "anterior" and occur before the text itself, such as the advertisements about a forthcoming publication of a book; (ii) "original" and appear in conjunction with the text, for example, a preface, and (iii) paratexts that appear subsequent to the text, such as re-editions of a book. Moreover, Genette and Maclean (1991, p. 264) differentiate between "posthumous" paratexts that appear following the death of the author and "anthumous" paratexts that may appear during the author's lifetime. Substantial paratexts are verbal, for example, prefaces, and they share the linguistic conventions of the text; but they can also assume other forms of expression, such as illustrations (Genette \& Maclean, 1991, p. 265).

The pragmatic status of a paratextual element describes "the nature of the addresser, of the addressee, degree of authority and responsibility of the first, illocutionary force of his message" (Genette \& Maclean, 1991, p. 266). The addresser is usually the author and/or the publisher but it may also be another person delegated to take on part of their responsibility. That is, "the addresser is defined by putative attribution and by assumed responsibility" (Genette \& Maclean, 1991, p. 266). Paratexts can be either "authorial" (written by the author) or "editorial" (designed by the publisher, e.g., a book cover), or feature divided authorship (e.g., an interview between the author and an interviewee). The addressee may be the general public (as in the title of a book) or the readers of the text (as in the preface of a book), or the author himself (in the form of diaries). Therefore, paratexts are either general, private or intimate (Genette \& Maclean, 
1991, p. 267). Responsibility for the text, according to Genette and Maclean (1991, p. 267), can be either "official" or "officious". The former describes a responsibility assumed by the author and/or the editor which they cannot deny (e.g., "anthumous" paratext). The latter occurs in authorial "epitext" (e.g., interviews) which can be disputed or denied by the author or the editor. Paratexts convey not only facts; they can also show authors' or editors' intentions or interpretations, as well as the author's decision, undertaking or advice (Genette \& Maclean, 1991, p. 268). Finally, the function of paratextual elements, which is empirical and diverse, is subordinate to the text, and so it determines its aspect and its existence (Genette \& Maclean, 1991, p. 268).

The analysis of the case study will be based on a combination of tools from the approaches discussed. More specifically, I have taken Serafini's framework as the overall framework, embedded the metafunction analysis to Serafini's structure level, and then further embedded the analysis of paratextual elements at the representational metafunction level. This combination of methods aims to provide a detailed explanation of the meaning created in each of these images, the purpose of which is to broaden the viewers' or the translators' knowledge of how meaning is shaped and can be interpreted.

\section{Case Study}

\subsection{Data}

This article analyses samples of Egyptian webcomics and GIFs from the period between 2012 and 2016. The samples have been collected from two Facebook pages: (i) Asa $7 b e$ Sarcasm Society ${ }^{5}$ and (ii) Islam Gawish Elwarka/The Paper ${ }^{6}$. The images are first produced and then published on the two Facebook pages; 50 GIFs (out of approximately 15000 ), and 50 webcomics (out of approximately 1,550) were examined. The sample collected is based on a number of topics that were politically significant at the time. These include: (i) presidential elections and constitutional referendums; (ii) Egypt under the leadership of Sisi, after the ousting of Morsi; (iii) the failure of the 25 January Revolution, and (iv) corruption in the security forces. The images are posted by the page's administrator, and created by members of each group (according to the pages' founders and co-founders). The samples chosen are typical images that correspond to some of the themes mentioned, and they are representative of images that contain complex cultural references (e.g., Egyptian films, pan-Arabism).

\subsection{Interviews}

The analysis of the case study is informed by interviews with the founders and cofounders of the two Facebook pages listed below. Although featuring some political content, they are not categorised as political pages because both of them also publish content on current social issues. They also publish on Twitter and Instagram but they are "liked" and followed by a larger number of people on Facebook.

- $\quad$ Asa7be Sarcasm Society as co-founded by Shady Sedky and Ahmed Abdel Aziz in 2012. Sedky is a web developer who has been working in this domain for around 15 years. According to Sedky, this page is the fourth biggest comic page online (followed by over 14 million people as at March 2018). It was established as a reaction to the violent events that took place in Egypt in 2011. Sedky and Abdel Aziz publish content that is produced by any member of their team but all the GIFs have their webpage signature on them. 
- Elwarka ("The Paper") was founded in January 2014 by Islam Gawish, a cartoonist and one of most well-known webcomic writers in Egypt. As at March 2018, his page had nearly two-and-a-half million followers. According to Gawish, it is accessed by different age groups, ranging from 10 to 60 , from various social and academic backgrounds, and is also accessed and followed by people in Egypt and the rest of the Arab world (Interview, 23 February 2017). Before the revolution, Gawish worked for the blog tahaya misr ("viva Egypt"), and he joined the "Arab Egyptian Newspaper" after the revolution. In the interview with Gawish, he states that he originally wanted to establish himself as a screenplay writer, but that he eventually started drawing comics and then launched his page. Gawish publishes content which he or one of his team members produce, but all the webcomics have the author's name and Gawish's signature on them.

In addition, I conducted an interview with the cartoonist and adult comics writer Makhlouf (7 March 2017), who publishes for Al-Masri Al-yawm and on his Facebook page. Makhlouf is also a co-founder of the adult satirical comic Tuk Tuk, founded in 2011 (Interview, 7 March 2017). As an emerging professional cartoonist whose political cartoons have been translated into English by Al-Masri Al-yawm's sister website Egypt Independent, Makhlouf's insights contribute in this article to establishing the difference between traditional cartoons and newly published forms of political satire, and to illustrating the difficulty of translating political satire.

The interviews contain information about the processes through which the images are created, about their broader context, and about the potential effects they have on a socially, politically and economically diverse audience. The interviews were conducted in Arabic, transcribed and, for the purpose of this article, subsequently translated into English.

\section{Analysis of data}

\subsection{Political Webcomics: Classroom (History lesson)}

\section{Socio-cultural context}

The comic represents the relationship between teacher and students which is based on trust and respect. It exemplifies the change this relationship has undergone in the past decade, particularly after the 25 January Egyptian Revolution, a period which had a negative impact on education in Egypt. It also draws attention to the unprecedented and rapid political changes that took place in Egypt between 2011 and 2014. 


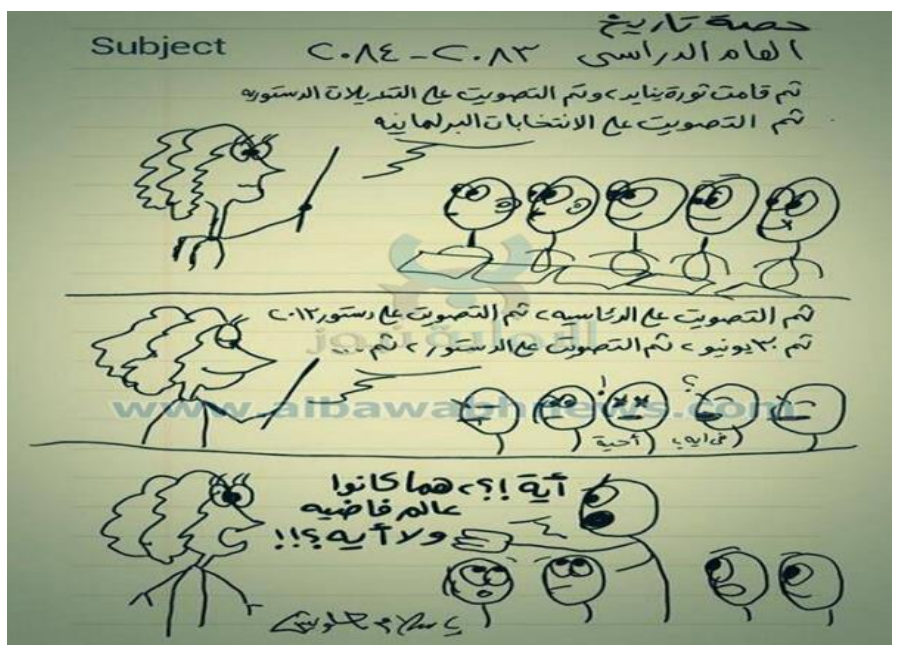

Figure 2: Webcomic: Classroom (History lesson)

\section{Translation:}

\section{History lesson:}

Academic year: 2083-2084

Teacher: Then the January Revolution started; then there was a referendum for constitutional reforms; then a vote for the parliamentary elections

Teacher: Then a vote for the presidential elections, then a referendum for the constitution, then the $30^{\text {th }}$ June revolution, then a referendum for the constitution, then ...

A Student thinking (added): what is going on? Another student thinking (added): oh dear!

\section{A shocked student (added): What?! Those people had nothing to do or what?!!}

\section{Perception}

\section{Context: History lesson}

Participants: female teacher and five students

Temporal element: History lesson about the Arab Spring in Egypt between 2011 and 2014, taking place in the future (academic year 2083-2084)

Content: The text is written in a similar font and colour in the first two frames and changed to a bold and bigger font in the last frame. The teacher's gaze and posture also change from one frame to another: first, she stands with her chin up, straight arm, raising a pointer; her posture then changes: the chin is lowered slightly, the arm is bent, and the 
pointer is used with less confidence; in the final frame, her eyes and mouth are wide open, her hands are by her side, and she has no pointer anymore. The students, on the other hand, look straight at the teacher in the first frame; in the second frame, questions and exclamation marks appear around two students' heads; in the third frame, one of the students stands up and points his arm and hand at the teacher while appearing to shout something - written in larger, bold font.

\section{Structure}

A structural analysis of this webcomic is discussed in the light of the following metafunctions:

Representational: The relationship between the represented participants (i.e., teacher and students) in this webcomic changes from that of dominant teacher-passive students when she presented the first set of facts about the revolution (see translation above), to less dominant teacher-puzzled students starting to think and question the many facts given to them by the teacher by uttering things like "What is going on?" and "Oh dear", to passive teacher-rebellious, active student(s), one of whom broke the barrier of silence, got angry at the teacher, and said: "What? Those people had nothing to do or what?!!". There are some multimodal resources in the image, indicating the three types of power relations.

The dominant teacher-passive student relationship is indicated by depicting the teacher looking at the students from a high angle. Other resources, such as the teacher's confident gaze and straight posture in the first frame, reflect the teacher's power over the students. Although in the second frame the teacher is still positioned at an angle above the students, suggesting she continues to be in control, there are other semiotic resources that suggest a loss of power and control. This is achieved by drawing the teacher with a less confident gaze and a less upright posture (chin down and stick lowered). In the same frame, the students' facial expressions and the use of textual elements (exclamation and question marks) show the students to be puzzled. The agency in the first two frames lies with the teacher who acts as the main source of information and as the person who has the authority to present this information. The illocutionary force intended by giving two sets of facts suggests the teacher's expectation that the students (as recipients) will accept them as they are.

The final frame shows a passive teacher-rebellious students relationship by placing the teacher and one student at eye level, which suggests, according to Kress and van Leeuwen (2006, p. 140), that the point of view is one of equality, and that a power difference is no longer at play. This lack of power difference is also expressed through salient elements in the third frame, that is, the bold and larger text font, a student standing almost at the same level as the teacher, the student's unnaturally long arm, and the teacher's facial expressions. The teacher's assumed power is also depicted in the long list of facts, joined together by the sequential particle "then", which she delivers without full stop or any form of interaction with the recipients (students), whom she expects to accept or agree with what she says. The shift of power relations eventually happens when one of the students questions the events the teacher describes.

Interpersonal: There are two lines of communication in this webcomic: one between the depicted participants themselves (see representational function) and one between the viewer and the depicted participants who are facing away from the viewer and thus have no interaction with him or her. This "allows the viewer to scrutinize the represented characters as though they were specimens in a display case" (Kress \& van Leeuwen, 2006, p. 43). The webcomic, as a form of mediated communication, shows that "the power of an image-producer must be transferred on to one or more represented participants" (Kress \& van Leeuwen, 2006, p. 136). The horizontal angle in this webcomic shows "whether the image-producer (and therefore, the viewer) is 'involved" 
with the represented participants or not" (Kress \& van Leeuwen, p. 136). In this case neither the producer nor the viewer is facing the represented participants; therefore they are not involved with the participants. Viewers seem to be just onlookers of the represented participants. Viewers could "identify with the view point encoded" but all of this depends on what they understand from the image.

Compositional: The compositional elements of the webcomic highlight the representational and interpersonal elements in order to underline the narrative. The layout of the webcomic is based on a classroom setting, with the teacher standing in front of the class. The students sit in a linear layout, suggesting that they are recipients rather than active participants. The producer "takes the readers by the hand, guiding them firmly through the text" (Kress \& van Leeuwen, 2006, p. 206). This is achieved in a number of ways: the title at the top of the image; three frames separated by lines are used to indicate the division of temporal elements between the different stages of the narrative, and the shift in power relations as discussed above. In addition, the author of the image uses salient verbal (font size and bold-faced writing) and non-verbal (facial expressions, student's long arm) recourses to highlight the shift in power relations expressed in this webcomic.

\section{Ideology}

The elements described in the perceptual and structural analysis are brought together at the level of ideology. Comics act as "powerful vehicles of ideology, whether in the service of power or in challenge to it" (Høigilt, 2017, p. 113); therefore they allow the viewer to question some of the elements provided by the comic artist. One of the elements highlighted in this comic is the shift in power relations between the teacher, usually the dominant figure in a classroom, and the students. Another noteworthy point is the fact that the artist makes explicit some of the thoughts young people might have. In this regard, Gawish (Interview, 23 February 2017) comments: "I present characters from real life; the comic makes you feel you have seen this in a certain character before or you have met this person before."

Having witnessed political events unfolding so quickly, the artist shows what students might think in the future, but he also indicates what they are already thinking today. Using a classroom as a context for this webcomic is intentional and highlights certain social elements the revolution has changed in Egypt - such as the teacher-student relationship. The change of power relations between the teacher and student, and the sacred role the teacher has assumed for a long time can now be questioned. Humour in this webcomic is represented by listing the number of elections and referendums held over the course of a few years (as highlighted by the particle "then"). Therefore, the political satire conveyed in this webcomic serves to achieve the function of criticising the rapid political changes that have taken place since the 25 January Revolution. The fact that the history lesson takes place in the future is also satirical and alludes to what future generations might think of the changes.

\subsection{Political Webcomics: World governance systems}

\section{Socio-cultural context}

"Kushari" is an Egyptian street food and a popular dish. It consists of many ingredients (small pasta, chick peas, brown lentils, and rice, topped with fried onions, served with a rich tomato sauce, and garlic dressing or chilli are added as desired ). 


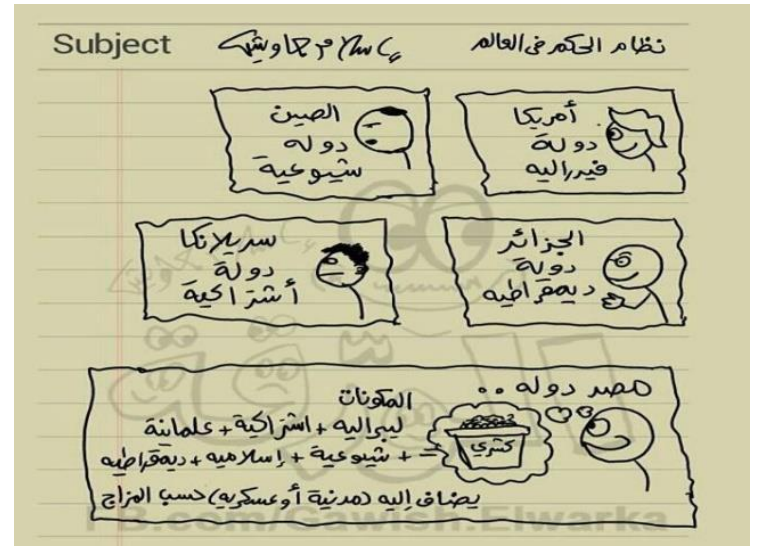

Figure 3: Comic about world governance systems

\section{Translation:}

Title: Governance systems in the world

\section{Frame one:}

Top right: America is a federal state

Top left: China is a communist state

\section{Frame two:}

Middle right: Algeria is a democratic state

Middle left: Sri Lanka is a socialist state

\section{Frame three:}

Egypt is a state whose governance system = 'kushari' (An Egyptian Popular dish, ingredients of which are: small pasta, chick peas, brown lentils, and rice, topped with fried onions, served with a rich tomato sauce, and garlic dressing or chilli are added as desired. (Bold faced information added)

Ingredients: Liberal + Socialist + Secular + Communist + Islamist + Democratic. Add (Civil or Military state) as desired.

\section{Perception}

Context: Governance systems in the world

Participants: Young people from different political systems: an American girl, young men from China, Algeria, Sri Lanka and Egypt.

Temporal element: 2012-2014

Content: The squares containing the text in the three frames increase in size from one frame to the next. A similar font is used in the first two frames; a smaller font is used in 
the last frame as it contains more text. The same colour is used in all the frames. The images of people representing different countries are shown; the profiles change slightly as the comic progresses: we see a woman with blonde hair in the first drawing, a man with short hair and narrow eyes in the second, a bald man in the third, a man with dark hair in the fourth, and a bald man with wide eyes in the last image. The last frame also contains a socio-cultural element represented by a drawing of "kushari". Further, two little bubbles emerge from the mind of the young Egyptian man about "kushari", as well as the "equals" sign and the "plus" symbol appearing in the ingredients.

\section{Structure}

A structural analysis of this webcomic is discussed in the light of the following metafunctions:

Representational: The first frame indicates two governance systems: the American federal system and the Chinese communist system. The second frame provides two more examples: the democratic system of Algeria and the socialist system of Sri Lanka. The third frame is concerned with the governance system in Egypt, which is depicted as being equal to "kushari". Components of this political system are: Liberal plus Socialist plus Secular plus Communist plus Islamist plus Democratic but-as in "kushari"-you can add Civil or Military as desired.

In the three frames, there is no interaction between the represented participants, that is, nationals from the different governance systems represented in this webcomic. They stand alone and each one is "looking at" the system they represent.

Interpersonal: There are two lines of communication in this webcomic: no communication between the depicted characters, while communication between the viewer and depicted characters (which are looking away and have therefore no interaction with the viewer) is also absent. In the third frame, the interactive participant (producer of the webcomic) uses a number of multimodal resources that suggest his or her confusion about the Egyptian governance system. This idea is supported by the thought bubbles and other salient elements represented in the form of an image of the popular Egyptian dish, as well as the change of gaze and the "equals" sign and the "plus" symbol. All these express the confusion of the creator of the comic about the political orientations in Egypt which equate to the ingredients of "kushari". In this comic as a whole, the viewers are mere onlookers and are not acknowledged by the represented participants.

Compositional: The webcomic has a title at the top, indicating the information value of the image, that is, the main theme of the narrative represented in the webcomic. This webcomic's most significant composition feature is a bigger box representing the Egyptian governance system in the last frame. In this frame, compositional elements are represented in the form of both popping thought bubbles shown above an image of the Egyptian dish and a change of gaze in the character depicted, alongside an "equals" sign and the "plus" symbol.

\section{Ideology}

Providing various examples of ruling systems across the world serves a purpose for the reader/viewer of the webcomic. For example, America represents countries that are often the focus of Egyptian society; the comic producer's reference to Algeria is also pertinent as it reflects the long-lasting relationship between the two Arabic countries. Reference to Sri Lanka appears also intentional as the author might assume that the political situation there is unknown to the public. It may also refer to Urabi, a well-known Egyptian activist who revolted against the British occupation in the late 1800s and went into exile to what 
is today known as Sri Lanka, hence the introduction of the famous proverb: "Ya Kharabi, Ya 'Urabi! (O, my ruin, o, 'Urabi!')" (Fahmy, 2011, p. 62).

The analogy between "kushari" and the Egyptian governance system is the prominent satirical element in this webcomic. The author shares the public's thoughts on Egypt's unstable political system and the absence of one recognised political party or system. In this regard, Gawish comments:

My webcomic page Elwarka/The Paper is a platform to express the people's views and feelings; I present topics which interest the public and I like to present their views with which I agree. (Interview, 23 February 2017)

\subsection{Political GIFs: Failure of the 25 January Revolution}

\section{Socio-cultural context}

This GIF is an example of how film content is remediated into a GIF and used as a social cue to communicate political ideas on social media. In other words, it is an example of "GIF literacy in action" (Gursimsek, 2016, p. 337). The GIF borrows scenes from an Egyptian film entitled "arees min giha 'amniyyah' - A bridegroom from the security forces". The film describes the story of a widowed father who dedicates his life to bringing up his daughter. He becomes so attached to her that he does not want her to marry and so rejects any man who proposes to her. But she falls in love with a security officer who proposes to marry her. They get engaged against her father's will, who then tries to convince her that the man is cheating on her by showing her a photo of him sitting with a lady during one of the security force operations. The conversation that takes place in this scene is borrowed for the GIF to show a dialogue between the father and his daughter about the political situation in Egypt three years after the 25 January Revolution. 


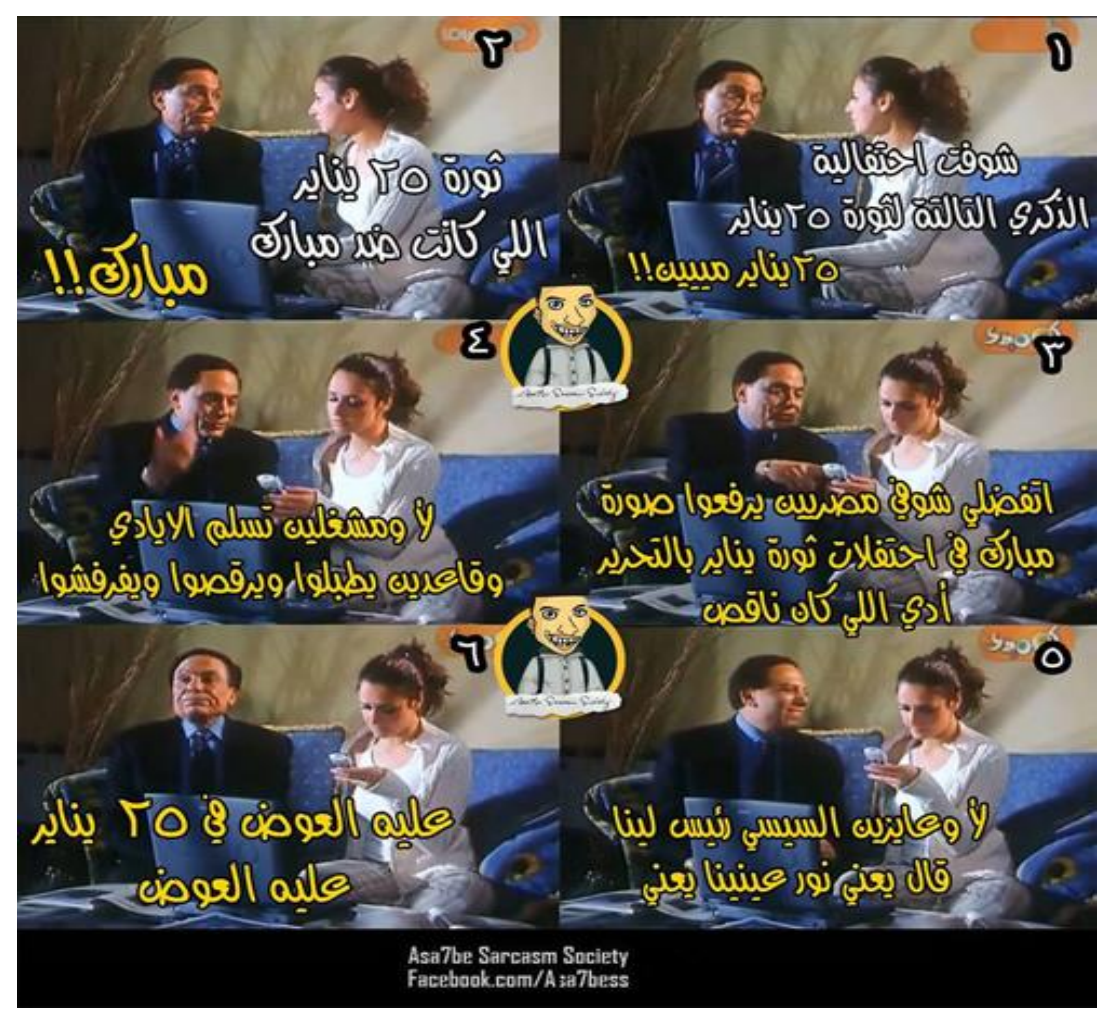

Figure 4: GIF about failure of the 25 January Revolution

\section{Translation:}

Frame one:

1. Top right: Daughter: Did you see the celebration of the third anniversary of the $25^{\text {th }}$ January Revolution? (Question mark added)

Father: Which $25^{\text {th }}$ January Revolution!!

2. Top left: Daughter: The $25^{\text {th }}$ January Revolution which was against Mubarak

Father: Mubarak!!

\section{Frame two:}

3. Middle right: Father: Look, Egyptians holding Mubarak's photo in Tahrir Square during the celebration of the $25^{\text {th }}$ January Revolution, this is ridiculous

4. Middle left: Father: They are listening to the song 'tislam elaayadi / God bless these hands, i.e. the army's hands (added)'; they are dancing and enjoying themselves

\section{Frame three:}

5. Bottom right: Father: And they wanted Sisi to be our president as if 'he is the light of our eyes' as he (Sisi) said before (added) 
6. Bottom left: Father: Allah (God) help us, no $25^{\text {th }}$ January Revolution any more, Allah (God) help us

\section{Perception}

Context: Celebrating the third anniversary of the 25 January Revolution

Temporal element: 25 January 2014

Participants: Father and daughter

Content: The GIF uses similar font and colour for each actor in all of the frames, except in images four and six, where the father's words appear in larger font. Paratextual elements can be found in the first two images in the form of two exclamation marks after a question and after the name "Mubarak". Posture and gaze change in the second frame when the father appears more engaged and closer to his daughter. But the daughter's facial expressions change in this frame and she looks more engaged, looking closely at the photos her father shows her about the events in Tahrir Square in an attempt to support his claims. In the last frame, the father cunningly smiles at her, but the daughter's face shows shock and she continues to look at the phone. In the final image, the father sits back and looks straight ahead.

\section{Structure}

A structural analysis of this webcomic is discussed in the light of the following metafunctions:

Representational: The represented participants, father and daughter, appear at the same level in the first image, which might suggest an equal relationship; yet the text in the three frames suggests a shift in dominance. This shift is indicated through the use of a number of multimodal resources. In the beginning, the father acts neutral and appears to be listening, but his gaze and responses show that he is dismissive, especially when he asks "which 25 Revolution?" and cries out in surprise when his daughter mentions Mubarak's name. The bigger font and the two exclamation marks underline this. In the second frame, the father takes the lead and seems more dominant when he attempts to dispute his daughter's idea that Egyptians are celebrating the 25 January Revolution. This is achieved through the use of temporal (anterior) and substantial (verbal) paratext (Genette \& Maclean, 1991, p. 265), such as the famous song about the role of the army in the 30th June Revolution. The last frame is the climax of the narrative; the father voices what he wants, leaves his daughter to reflect on it and potentially changes her viewpoint. A number of resources, that is, temporal (anterior) and substantial (verbal) paratext (Genette \& Maclean, 1991, p. 265), are being used to support his intention: he quotes Sisi's famous saying "You are the light of our eyes"; his facial expressions and gaze at the end indicate that he is at ease and neutral; the daughter's facial expressions of shock in the second and third frames; and finally by the bigger font in the last image which puts an emphasis on the message that the father wants to convey (i.e., failure of the revolution).

Interpersonal: The characters are placed in the middle of the page, that is, "in the middle of the social distance" (Serafini, 2010, p. 96). The viewer is the onlooker. This idea is confirmed by Sedky: "As authors of these GIFs we aim to highlight a situation or a problem for amusement, not for the sake of solving it ourselves. We think if we show it to the people, this could help in solving it" (Interview, 31 October 2016). The represented participants are facing each other in most of the frames, and they are not directly facing the viewer, which suggests that the viewers are mere onlookers, just as in regular films 
where they are not acknowledged by the represented participants. Only in the last image does the father look away from his daughter and look ahead, which may suggest that the producer of the image has "unconsciously aligned himself/herself" (Kress \& van Leeuwen, 2006, p. 136) with the father and the message he conveys.

Compositional: Dividing lines between frames supported by the number of images in the GIF allow the reader to see the progress of the narrative. The colour used in the text and the images borrowed from the film enable the reader to make a link between the film and the political viewpoint discussed in the GIF. Sedky confirms this idea:

They are more appealing to the public than normal traditional cartoons as they can relate to them easily: we use them for amusement and fun as well passing a view point. (Interview, 31 October 2016)

Brief statements - one word in the second image coupled with exclamation marks, and a short closing remark in the final image in larger font - are used to establish strong and persuasive views. Similarly to the father, as indicated before, the facial expressions of the daughter help to highlight the progress of the narrative. The father's expressions serve a similar function (see interpersonal function). Diverting his gaze from his daughter at the end suggests that he has achieved what he wanted to achieve.

\section{Ideology}

In this GIF, satire is implicit in the overall narrative about the 25 January Revolution celebration, which instead celebrates Mubarak, calls for the Army and demands Sisi (a military personality) to run for the presidency. One of the depicted participants, the father, symbolises those Egyptians who, after the 30th June Revolution, were able to foresee the country's political situation. The second depicted participant, the daughter, on the other hand, symbolises the hopeful youth who think that the 25 January Revolution is the way for real political change. This optimistic point of view seems to vanish when the daughter faces the reality of what is happening in Tahrir Square. The final statement made by the father represents what the majority of supporters of the 25 January Revolution think.

\section{Concluding remarks}

The purpose of this article was to examine a sample of Egyptian webcomics and GIFs published on Facebook. This method of analysis focused more on web-specific content because the examples are newly emerging forms of political satire after the Arab Spring. These webcomics are also printed in books now and sold in the bookshops and at the book fairs in Egypt. This same method of analysis could be used to analyse traditional print comics too.

The authors of these images focus on concrete image-making. For example, Islam Gawish, author of the webcomic samples analysed in this article, produces webcomics and article then publishes them online. He has his own specific style in his webcomics that should not be generalised to all the webcomics published on his page, especially not those which are produced by other authors. Although this comparison is beyond the scope of this article, it is worth mentioning that Gawish presents no interaction or involvement between represented participants and the viewers, who appear to be mere onlookers and who are allowed to "scrutinize the represented characters as though they were specimens in a display case" (Kress \& van Leeuwen, 2006, p. 43).

The samples analysed showed that authors produce images which contain an abundance of cultural references and therefore pose significant challenges for the translator, possibly more so than for translators of traditional cartoons which generally 
attach more importance to text than to images (Høigilt, 2017, p. 115). Drawing on a multimodal social semiotic framework, the sample analysis of webcomics and GIFs highlights the integration between both the verbal and visual modes and the paratextual elements when they are being translated because all of these contribute to facilitating the viewer's or the translator's interpretation of the message. It merits mentioning that some strategies and techniques used in interlingual translation may contribute to achieving this integration. These strategies and techniques are discussed in the following paragraphs.

When Arabic webcomics and GIFs are being translated for an international audience, it is expected that culture-specific elements, for example, face-threatening acts (Brown \& Levinson, 1987) prominent in the visual mode need to be changed (Zitawi, 2008), adapted or at times even removed when translating into languages such as English or Chinese (O'Sullivan, 2013). This article, however, does not suggest general changes to the visual mode, that is, frames, colours, etc. On the contrary, what is important is to highlight the social context of the visual mode, that is, the images, as it contributes to the message of the verbal mode. One strategy translators might draw on to support the integration between the visual and the verbal modes and to highlight the salient elements in both modes is foreignization (Venuti, 1998, 1995/2008). There are a number of other techniques that can be followed (Nida, 1964; Vinay \& Darbelnet, 1958/1995; Molina \& Hurtado, 2002), such as compensation which itself will involve other techniques such as explicitation. If we refer back to one of the examples presented above (see Figure 2), translators could compensate for the students' uncertainty and puzzlement-indicated by the change in facial expressions and the funny eyes and eyebrows alongside the question and exclamation marks - through explicitation (Vinay \& Darbelnet, 1958/1995). By that is meant making explicit what these signs represent by adding: "one student is thinking ..." and "another student is thinking ...".

Compensation (Molina \& Hurtado, 2002) can also be used to account for the salient element in the last frame, that is, the pupil's unusually long-arm pointing at the teacher, by the addition (Nida, 1964) of what this means for the progress of the comic's narrative. This can be done by adding "a shocked pupil" or "an angry pupil" to the translation. Regarding the verbal mode, maintaining the textual elements of the comic in its translation is also important. This can be achieved by keeping the repetition of the linking word "then" and the recurring punctuation marks which add to the narrative. Keeping other textual elements such as the bold, larger fonts will transfer specific details of the narrative to the target readership and will integrate the verbal and visual modes of the narrative.

The focal point of the webcomic shown in Figure 3 is the interactive participant's uncertainty about the nature of the Egyptian governance system. This is expressed through the use of a number of multimodal resources, such as the reference to the Egyptian dish "kushari". This culture-specific element can be borrowed (Vinay \& Darbelnet, 1958/1995) in the translation but it can also be translated through explicitation (Vinay \& Darbelnet, 1958/1995) (popular Egyptian dish and by listing the ingredients of the dish). The textual features given in the source text, such as the thought bubbles, are an "invaluable source for the translator" as they can offer "an understanding of the basic principles governing the choice of work" (Salor \& Marasligil, 2013, p. 5). Other elements, such as the "equals" sign and the "plus" sign, are to be retained in the target text (rather than using commas, for example) and added to the ingredients of the dish in order to create a similar effect to the one intended by the producer of the webcomic.

For the webcomic shown in Figure 4 a number of verbal and anterior paratextual elements need to be paid specific attention to in the translation. Regarding the verbal mode, elements such as the bigger font and exclamation marks (used in place of questions marks) are to be kept. Other elements such a question mark may be added (Nida, 1964) to "which 25 January Revolution?". Borrowing and adaptation (Vinay \& Darbelnet, 1958/1995) may also be used to translate culture-specific terms such as "Allah/God". In fact, repetition of the phrase "Allah/God help us" is useful to highlight what the 
interactive and/or represented participants aim to convey. Anterior paratext is essential to this webcomic, for example, the reference to a song made for the Army after the 30th June Revolution which ended up ousting Morsi. In addition to translating this song by borrowing and/or literal translation (Vinay \& Darbelnet, 1958/1995), an addition (Nida, 1964) can be made, that is, "the army's hands" or integrating this into the translation itself: "Allah/God bless the Army/the Army's hands". The translator might also use addition (Nida, 1964) when translating "as if he is the light of our eyes" and refer to Sisi, who uttered the very words during a celebration: "you are the light of our eyes/you are dear to us" in one of the celebrations.

There are some limitations to the methodology discussed here because its application to a large corpus is time-consuming; it is, however, beneficial for the examination of the way in which multimodal elements in Arabic webcomics and GIFs are reproduced in English translations. And although not many translations of these genres are currently available, creating a corpus of political webcomics and GIFs translated by professional translators is potentially a valuable future endeavour, as is their comparison to translated political cartoons. It would also be useful to discuss the reception of the translation of these genres into English for an enhanced transnational audience.

\section{Acknowledgement}

I wish to thank my colleagues Dr Sara Ramos Pinto and Dr Elisabetta Adami for reading and commenting on this paper.

\section{References}

Aiello, G. (2006). Theoretical advances in critical visual analysis: Perception, ideology, mythologies, and social semiotics. Journal of Visual Literacy, 26(2), 89-102.

Andersen, T. H., Morten B., Maagerø, E., \& Tønnesen, E. S. (2015). Social semiotics: Key figures, new directions. London: Routledge.

Asimakoulas, D. (2016). Aristophanes in comic books: Adaptation as metabase. Meta, 61(3), 553557.

Bassnett, S., \& Lefevere, A. (Eds.). (1990). Translation, history and culture. London: Pinter.

Bassnett, S., \& Lefevere, A. (1998). Constructing culture. Clevedon: Multilingual Matters.

Baker, Mona (Ed.). (2015). Translating dissent: Voices from and with the Egyptian revolution. London: Routledge.

Borodo, M. (2015). Multimodality, translation and comics. Perspectives, 23(1), 22-41.

Brown P., \& Levinson, S. (1987). Politeness: Some universals in language usage. Cambridge: Cambridge University Press.

Chesterman, A. (2005). Consilience in translation studies. Revista Canaria de Estudios Ingleses, 51, 19-32.

Chesterman, A. (2007). Bridge concepts in translation sociology. In M. Wolf \& A. Fukari (Eds.), Constructing a sociology of translation (pp. 171-183). Amsterdam: John Benjamins.

Duncum, P. (2004). Visual culture isn't just visual: Multiliteracy, multimodality, and meaning. Studies in Art Education, 45(3), 252-264.

Gambier, Y. (2009). Challenges in research on audiovisual translation. Translation Research Project 2. Intercultural Studies Group, Tarragona. Available at: http://isg.urv.es/publicity/isg/publications/ trp_2_2009/chapters/gambier.pdf. [Accessed 09 September 2016]

Genette, G., \& Maclean, M. (1991). Introduction to the paratext. New Literary History, 22(2), 261272.

Gursimsek, O. A. (2016). Animated GIFs as vernacular graphic design: Producing Tumblr blogs. Visual Communication, 15(3), 329-349. 
Guyer, J. (2017). Speech bubbles: Comics and political cartoons in Sisi's Egypt. In T. Cambanis \& M. W. Hanna (Eds.), Arab Politics Beyond the Uprisings. Available at: https://tcf.org/content/ report/speech-bubbles/ [Accessed 15 May 2017]

Fahmy, Z. (2011). Ordinary Egyptians: Creating the modern nation through popular culture. Stanford, CA: Stanford University Press.

Halliday, M. A. K., \& Matthiessen, C. (1985). An introduction to functional grammar. London: Routledge.

Halliday, M. A. K. (2014). Halliday's introduction to functional grammar (4th ed), revised by C. M.I.M. Matthiessen. London: Routledge.

Høigilt, J. (2017). Egyptian comics and the challenge of patriarchal authoritarianism. International Journal of Middle East Studies, 49, 111-113.

Kaindl, K. (1999). Thump, whizz, poom: A framework for the study of comics under translation. Target, 11(2), 263-288.

Kaindl, K. (2004). Multimodality in the translation of humour in comics. In E. Ventola, C. Charles, \& M., Kaltenbacher (Eds.), Perspectives on multimodality (pp. 173-192). Amsterdam: John Benjamins.

Kovačič, I. (1995). Reception of subtitles: The non-existent ideal viewer. Translatio (FIT Newsletter), 14(3-4), 376-383.

Kress, G. (2003). Literacy in the new media age. London: Routledge.

Kress, G. (2010). Multimodality: A social semiotic approach to contemporary communication. London: Routledge.

Kress, G., \& van Leeuwen, T. (1996). Reading images: The grammar of visual design. London: Routledge.

Kress, G., \& van Leeuwen, T. (2006). Reading images. the grammar of visual design (2nd ed.). London: Routledge.

Kristeva, J. (1980). Desire in language: A semiotic Approach to language and art. Trans. Thomas Gora, Alice Jardine and Leon S. Roudiez, ed. Leon S. Roudiez. New York, NY: Columbia University Press.

Lankshear, C., \& Knobel, M. (Eds.). (2008). Digital literacies: Concepts, policies and practices. Oxford: Peter Lang.

Mehrez, S. (2012). Translating Egypt's revolution: The language of Tahrir. Cairo: AUC Press.

Mohamed, D. (2015). On translating a superhero: Language and webcomics. In M. Baker (Ed.), Translating dissent: Voices from and with the Egyptian revolution (pp 137-146). London: Routledge.

Molina, L., \& Hurtado Albir, A. (2002). Translation techniques revisited: A dynamic and functional approach. Meta, 47(4), 498-512.

Nida, E. A. (1964). Toward a science of translating with special reference to principles and procedures involved in Bible translating. Leiden: E.J. Brill.

O'Sullivan, C. (2013). Introduction: Multimodality as challenge and resource for translation. The Journal of Specialised Translation, 20, Available at www.jostrans.org/issue20/art_osullivan.pdf [Accessed 20 October 2017]

Pederson, J. (2005). How is culture rendered in subtitles? MuTra 2005-challenges of multidimensional translation: Conference proceedings, 1-18.

Pederson, J. (2007). Cultural interchangeability: The effects of substituting cultural references in subtitling. Perspectives, 5(1), 40-48.

Pederson, J. (2011). Subtitling norms for television: An exploration focusing on extralinguistic references. Amsterdam: John Benjamins.

Salor, E., \& Marasligil, C. (2013) Translating comics: It's not just In the bubble. Norwich Papers, 21, $1-10$.

Schäffner, C., \& Adab, B. (1997). Translation as intercultural communication-contact as conflict. In M. Snell-Hornby, Z. Jettmarova \& K. Kaindl (Eds), Translation as intercultural communication (pp. 325-337). Amsterdam: John Benjamins. 
Serafini, F., \& Ladd, S. M. (2008). The challenge of moving beyond the literal in literature discussions. Journal of Language and Literacy Education, 4(2), 6-20.

Serafini, F. (2010). Reading multimodal texts: perceptual, structural and ideological perspectives. Children's Literature in Education, 41, 85-104.

Singerman, D., \& Amar, P. (2006). Cairo cosmopolitan: Politics, culture, and urban space in the new globalized middle East. Cairo: The American University Press.

Smith-Shank, D., L. (Ed.). (2004). Semiotics and visual culture: Sights, signs, and significance, Reston, VA: National Art Education Association.

Staiger, J. (1992). Interpreting films studies in the historical reception of American cinema. USA: Princeton University Press.

Stolnitz, J. (1960). Aesthetics and the philosophy of art criticism. Boston, MA: Houghtonn Mifflin Company.

Sturken, M., \& Cartwright, L. (2001). Practices of looking: An introduction to visual culture. Oxford: Oxford University Press.

The Arab Comix Project [online]. Available at http://arabcomixproject.weebly.com/comic-strips-comic-books.html [Accessed 18 December 2017]

The Institute of Current World Affairs (2015). From Beirut: the origin of Arabic comics. Available at https://www.icwa.org/from-beirut-the-origin-story-of-arab-comix/ [Accessed 25 September 2017]

Veloso, F., \& Bateman, J. (2013). The multimodal construction of acceptability: Marvel's civil war comic books and the PATRIOT Act. Critical Discourse Studies, 10(4), 427-443.

Venuti, L. (1998). The scandals of translation: Towards an ethics of difference. London: Routledge.

Venuti, L. (1995/2008). The translator's invisibility: A history of translation, London: Routledge.

Vinay, J.-P., \& Darbelnet, J. (1958/1995). Comparative stylistics of French and English: A methodology for translation, (trans.) by Sager J. C. \& M.-J. Hamel. Amsterdam: John Benjamins.

Willems, W. (2011). Comic strips and "the crisis": Postcolonial laughter and coping with everyday life in Zimbabwe. Popular Communication, 9(2), 126-145.

Zanettin, F. (Ed.) (2008). Comics in translation. London: Routledge.

Zanfei, A. (2008). Defining webcomics and graphic novels. International Journal of Comic Art, 10(1), $55-61$.

Zitawi, G. (2008). Disney comics in the Arab culture(s): A pragmatic perspective. In F. Zanettin (Ed.), Comics in Translation (pp. 152-171). London: Routledge.

1 For information on the history of comics, see Salor and Marasligil, 2013.

2 For more information on the longstanding intertextuality between East and West in Egyptian urban culture, see Singerman and Amar, 2006.

3 For information on culture-specific concepts and cultural references, see Bassnett and Lefevere, 1990, 1998; Schäffner and Adab, 1997; Pederson, 2005, 2007, 2011, among others.

4 It is important to differentiate between reception and perception. The former is a concept introduced by Reception Studies, which considers 'how texts and art works are consumed' (Staiger, 1992, p. 11). It describes 'the readers' reaction' to the message given in a political webcomic or a GIF, that is, their mental or emotional feeling; 'their response', that is, what they actually do, and the 'repercussions', that is, whether or not this message presented in the webcomic or GIF will have any impact on their political stance or their understanding of the political situation (Chesterman, 2005, p. 27 and 2007, p. 179; Gambier, 2009; Kovačič, 1995).

$5<\mathrm{https} / / /$ www.facebook.com/asa7bess/>

$6<$ https://www.facebook.com/Gawish.Elwarka/.> 